\title{
ANALISIS PENGARUH MOTIVASI KERJA DAN LINGKUNGAN KERJA TERHADAP KINERJA APARAT DESA
}

\author{
Wahna Widhianingrum \\ Fakultas Ekonomi, Universitas Muhammadiyah Ponorogo, Jl. Budi Utomo No. 10 Ponorogo \\ Email :wahnawidhia@gmail.com
}

\begin{abstract}
The problem in this study is how much influence work motivation and work environment have on the performance of Kaibon village officials. The purpose of this study was to determine how much influence work motivation and work environment had on the performance of Kaibon village officials.The type of research used is quantitative with an associative approach. The technique of collecting data through observation, questionnaires and documentation. Whereas the right statistical analysis technique is used, namely multiple regression analysis using 2 explanatory variables and 1 response variable. This study uses two variables, namely: the response variable in the form of the performance of village officials $(Y)$ and explanatory variables in the form of work motivation (X1) and work environment (X2). As for the types of data sources, this research is primary data, namely data obtained directly from the source or place where the research was conducted.In this study, researchers determined a total sample of 55 village officials. Determination of this quota is based on consideration of the number of population of village officials in the Kaibon Village Office of 75 . The sample determination is saturated sampling. Data obtained using SPSS 20 (Statistical Product and Service Solutions).The results of this study indicate that based on the results of research that the researchers did work motivation variables (X1) and work environment (X2) gave a significant influence on the performance variable apparatus ( $Y$ ) of Kaibon Madiun Village.
\end{abstract}

Keywords: Apparatus Performance. Work Environment, Work Motivation

\section{PENDAHULUAN}

Setiap badan pemerintah baik di lingkungan desa, kota atau kabupaten, provisi bahkan pemerintah pusat dituntut untuk memaksimalkan sumberdaya manusia dan pengelolaan sumberdaya manusia yang tersedia. Pengelolaan ini tidak terlepas dari motivasi kerja dan lingkungan kerja yang mendukung terciptanya kinerja yang optimal. Aparat desa merupakan aset sumberdaya manusia terpenting demi terwujudnya stabilitas peran kantor desa dalam memberikan pelayanan terhadap masyarakat. Peran aparat desa sangatlah penting sebagai pemikir, perencana, pelaksana dan pengendali aktivitas pemerintahan di lingkungan desa.Karena pentingnya peran aparat desa, aparat desa perlu mendapat perhatian lebih agar tercapainya tujuan pemerintahan desa.

Terdapat beberapa faktor yang mempengaruhi kinerja aparat desa di antaranya motivasi kerja dan lingkungan kerja. Idealnya, semakin tinggi motivasi kerja aparat desa, maka aparat desa juga akan semakin rajin dalam melaksanakan tugasnya sebagai aparat desa. Begitu sebaliknya, semakin rendah motivasi aparat desa maka aparat desa juga semakin malas untuk melaksanakan tugasnya sebagai aparat desa. Hal ini pasti akan berdampak tidak optimalnya kinerja dari aparat desa. 
Kinerja merupakan pencapaian tugas, dimana dalam bekerja harus sesuai dengan program kerja dalam mencapai visi, misi, dan tujuan. Menurut Mathis dan Jackson (2006) faktor yang mempengaruhi kinerja yaitu kemampuan untuk pekerjaan tersebut dan tingkat usaha yang dicurahkan. Menurut Mathis dan Jackson (2006), motivasi adalah keinginan dalam diri seseorang yang menyebabkan orang tersebut bertindak. Biasanya orang bertindak karena suatu alasan untuk mencapai tujuan. Memahami motivasi sangatlah penting karena kinerja, reaksi terhadap kompensasi dan persoalan sumber daya manusia yang lain dipengaruhi dan mempengaruhi motivasi.

Menurut Joko Purnomo (2008) dalam penelitiannya mengenai kepemimpinan, motivasi kerja, dan lingkungan kerja, terhadap kinerja karyawan menunjukkan hasil yang signifikan. Di mana variable motivasi kerja dan lingkungan yang mempunyai pengaruh yang signifikan terhadap kinerja karyawan. Penelitian ini sendiri dilakukan terhadap pegawai negeri sipil pada Dinas Kehutanan dan Perkebunan Kabupaten Jepara. terbukti mempengaruhi. Sedangkan menurut Lucky Wulan Analisa (2011) dalam penelitiannya mengenai pengaruh motivasi kerja dan lingkungan kerja terhadap kinerja pada studi kasus Dinas Perindustrian dan Perdagangan Kota Semarang, menyebutkan bahwa kedua variabel penjelas memberikan pengaruh positif terhadap kinerja karyawan. Dalam penelitian ini, faktor - faktor tersebut dianalisis untuk menentukan pengaruh motivasi kerja dan lingkungan kerja terhadap kinerja aparat desa Kaibon, Madiun.

Sumber daya manusia berperan dalam mengolah dan memanfaatkan sumber daya dan material sehingga menjadi produk. Oleh karena itu untuk meningkatkan kinerja, perlu diperhatikan agar sumber daya manusia dapat bekerja secara efisien dan menampilkan kinerja yang bisa memberi sumbangan terhadap produktivitas merupakan masalah mendasar dari berbagai konsep manajemen dan kepemimpinan.Kinerja mengacu pada prestasi kerja aparat diukur berdasarkan standard atau kriteria yang telah ditetapkan.Pengelolaan untuk mencapai kinerja aparat yang sangat tinggi terutama untuk meningkatkan kinerja secara keseluruhan.

Kantor Desa Kaibon Madiun Adalah salah satu instansi pemerintah dalam lingkup pedesaan. Penelitian ini dilakukan untuk mengetahui apakah motivasi dan lingkungan kerja mempunyai pengaruh signifikan terhadap kinerja aparat dalam suatu organisasi pemerintah dalam hal ini kantor desa. Berdasarkan uraian latar belakang tersebut diatas, maka dapat diajukan sebuah penelitian dengan judul "Analisis Pengaruh Motivasi Kerja dan Lingkungan Kerja Terhadap Kinerja Aparat Desa di Kantor Desa Kaibon, Madiun”.

\section{METODE PENELITIAN}

Tempat penelitian ini berada di Kantor Desa Kaibon, Kecamatan Geger, Kabupaten Madiun.Jenis penelitian yang digunakan adalah kuantitatif dengan pendekatan asosiatif.Teknik pengumpulan data melalui observasi, kuesioner dan dokumentasi.Sedangkan teknik analisis statistika yang tepat digunakan yaitu analisis regresi berganda dengan menggunakan 2 variabel penjelas dan 1 variabel respon. Penelitian ini menggunakan dua variabel yaitu: variabel respon berupa kinerja aparat desa (Y) dan variabel penjelas berupa motivasi kerja (X1) dan lingkungan kerja (X2). Adapun jenis dari sumber data, penelitian ini yaitu data primer yaitu data yang diperoleh langsung dari sumber atau tempat dimana penelitian dilakukan.

Pada penelitian ini, peneliti menetapkan jumlah sampel sebanyak 55 aparat desa.Penetapan 
kuota ini berdasarkan pertimbangan jumlah populasi aparat desa yang ada di Kantor Desa Kaibon sebesar 75.Penentuan sampel yang dilakukan adalah sampling jenuh.Data yang diperoleh dengan menggunakan bantuan SPSS 20 (Statistical Product and Service Solutions).

\section{HASIL DAN PEMBAHASAN}

Hasil perhitungan validitas menunjukkan bahwa 13 indikator pada variabel motivasi kerja dinyatakan valid karena karena mempunyai nilai pearsoncorrelation yang lebih besar dari $r$ tabel $(0,265)$ dan nilai signifikansi yang kurang dari nilaialpha $(0,05)$ sehingga variabel motivasi kerja, variabel lingkungan kerja, dan variabel kinerja dapat digunakan untuk pengujian tahap selanjutnya.

Nilai reliabilitas kedua koefisien Cronbach Alfa dinyatakan reliabel karena lebih besar dari 0,6. Dengan demikian semua indikator pada ketiga variabel yaitu variabel motivasi kerja, lingkungan kerja dan variabel kinerja dalam penelitian dinyatakan reliabel dan selanjutnya dapat digunakan dalam penelitian.

Analisis pengaruh variabel motivasi kerja (X1) dan lingkungan kerja (X2) terhadap variabel kinerja aparat (Y) Desa Kaibon Madiun dilakukan menggunakan analisis regresi linier berganda.Analisis regresi linier berganda digunakan untuk mengetahui pengaruh variabel motivasi kerja (X1) dan lingkungan kerja (X2) terhadap variabel kinerja aparat (Y) Desa Kaibon Madiun.

Kriteria pengujian menyatakan apabila nilai VIF lebih kecil dari 10 atau nilai tolerance lebih besar dari 0.1 maka dinyatakan tidak terdapat gejala multikolinier.Adapun hasil VIF dan Tolerancediketahui semua variabel independen menghasilkan nilai VIF yang lebih kecil dari 10 dan nilai tolerance lebih besar dari 0.1.Dengan demikian analisis regresi pada penelitian ini dinyatakan tidak mengandung gejala multikolinier.

Pengujian asumsi normalitas pengaruh motivasi kerja (X1) dan lingkungan kerja (X2) terhadap kinerja aparat (Y) Desa Kaibon Madiun menghasilkan statistik uji Kolmogorov Smirnov sebesar 1,113 dengan probabilitas sebesar 0,168. Hasil ini menunjukkan bahwaprobabilitas >level of significant $(\alpha=5 \%$ ), sehingga $\mathrm{H0}$ diterima. Hal ini berarti residual dinyatakan berdistribusi normal.Dengan demikian asumsi normalitas terpenuhi.

Pengujian asumsi heteroskedastisitas menunjukkan bahwa probabilitas untuk semua variabel >level of significant $(\alpha=5 \%)$. Hal ini berarti residual dinyatakan memiliki ragam yang homogen.Dengan demikian asumsi heteroskedastisitas terpenuhi.

Hasil pengujian pengaruh variabel motivasi kerja (X1) dan lingkungan kerja (X2) terhadap variabel kinerja aparat (Y) Desa Kaibon Madiun dapat dilihat melalui tabel 1 berikut : 
Tabel 1. Koefisien Masing-masing Variabel

\begin{tabular}{|c|c|c|c|c|}
\hline Variabel & Koefisien & $\begin{array}{c}\text { Standardized } \\
\text { Coeffisient }\end{array}$ & Tstatistic & Prob \\
\hline Konstanta & 16,551 & & 4,586 & 0,000 \\
\hline $\begin{array}{l}\text { Motivasi } \\
\text { Kerja (x1) }\end{array}$ & 0,248 & 0,256 & 2,589 & 0,012 \\
\hline $\begin{array}{l}\text { Lingkungan } \\
\text { Kerja (x2) }\end{array}$ & 0,453 & 0,634 & 6,409 & 0,000 \\
\hline $\begin{array}{l}\text { Fstatistic = } \\
48,413 \\
\text { R-squared = } \\
0,651\end{array}$ & & $\begin{array}{l}\text { Prob }=0,000 \\
\text { Adj.R- } \\
\text { squared = } \\
0,637\end{array}$ & & \\
\hline
\end{tabular}

Besarnya kontribusi variabel motivasi kerja (X1) dan lingkungan kerja (X2) terhadap variabel kinerja aparat (Y) Desa Kaibon Madiun dapat diketahui melalui koefisien determinasinya $\left(\operatorname{adj} \mathrm{R}^{2}\right.$ ) yaitu sebesar 0,637. Hal ini berarti keragaman variabel kinerja aparat.

(Y) Desa Kaibon Madiun dapat dijelaskan oleh variabel motivasi kerja (X1) dan lingkungan kerja (X2) sebesar 63,7\%, atau dengan kata lain kontribusi variabel motivasi kerja (X1) dan lingkungan kerja (X2) terhadap variabel kinerja aparat (Y) Desa Kaibon Madiun sebesar 63,7\%, sedangkan sisanya sebesar 36,3\% merupakan kontribusi dari variabel lain yang tidak dibahas dalam penelitian ini.

Pengujian hipotesis simultan digunakan untuk mengetahui ada tidaknya pengaruh variabel motivasi kerja (X1) dan lingkungan kerja (X2) terhadap variabel kinerja aparat (Y) Desa Kaibon Madiun. Kriteria pengujian menyatakan jika nilai Fhitung $\geq$ Ftabel atau probabilitas level of significance maka terdapat pengaruh signifikan secara simultan variabel motivasikerja (X1) dan lingkungan kerja (X2) terhadap variabel kinerja aparat (Y) Desa Kaibon Madiun. Pengujian hipotesis secara simultan menghasilkan nilai Fhitung sebesar 48,413 dengan probabilitas sebesar 0,000 . Hasil pengujian tersebut menunjukkan probabilitas <level ofsignificance ( $=5 \%$ ). Hal ini berarti terdapat pengaruh signifikan secara simultan (bersama-sama) variabel motivasi kerja (X1) dan lingkungan kerja (X2) terhadap varabel kinerja aparat (Y) Desa Kaibon Madiun.

Pengujian hipotesis parsial digunakan untuk mengetahui ada tidaknya pengaruh variabel motivasi kerja (X1) dan lingkungan kerja (X2) terhadap variabel kinerja aparat (Y) Desa Kaibon Madiun. Kriteria pengujian menyatakan jika nilai thitung $\geq$ ttabel atau probabilitas <levelof significancemaka terdapat pengaruh signifikan secara individu pengaruh variabelmotivasi kerja (X1) terhadap variabel kinerja aparat (Y) Desa Kaibon Madiun dan pengaruh variabel lingkungan kerja (X2) terhadap variabel kinerja aparat (Y) Desa Kaibon Madiun.

Pengujian hipotesis secara parsial variabel motivasi kerja (X1) menghasilkan nilai t hitung sebesar 2,589 dengan probabilitas sebesar 0,012. Hasil pengujian tersebut menunjukkan probabilitas <level of significance $(=5 \%)$. Hal ini berarti terdapat pengaruh yang signifikan variabel motivasi kerja (X1) terhadap variabel kinerja aparat (Y) Desa Kaibon Madiun.

Pengujian hipotesis secara parsial variabel lingkungan kerja (X2) menghasilkan nilai $t$ hitung sebesar 6,409 dengan probabilitas sebesar 0,000. Hasil pengujian tersebut menunjukkan 
probabilitas <level of significance $(=5 \%)$. Hal ini berarti terdapat pengaruh signifikan variabel lingkungan kerja (X2) terhadap variabel kinerja aparat (Y) Desa Kaibon Madiun.

Pengujian hipotesis secara parsial variabel konstanta menghasilkan nilai t hitung sebesar 4,586 dengan probabilitas sebesar 0,000. Hasil pengujian tersebut menunjukkan probabilitas $<$ level of significance $(=5 \%)$. Hal ini berarti terdapat pengaruh signifikan secara parsialkonstanta terhadap variabel kinerja aparat (Y) Desa Kaibon Madiun.

Persamaan regresi dari hasil estimasi analisis regresi linier berganda adalah:

$\mathrm{Y}=\boldsymbol{\beta 0}+\boldsymbol{\beta 1} \mathrm{X} 1+\boldsymbol{\beta 2} \mathrm{X} 2+\varepsilon$

$Y=16,551+0,248 X 1+0,453 X 2$

Persamaan ini menunjukkan hal-hal sebagai berikut :

1) Konstanta sebesar 16,551 mengindikasikan bahwa apabila variabel motivasi kerja (X1) dan lingkungan kerja (X2) bernilai konstan (tidak berubah) maka besarnya perubahan variabel kinerja aparat (Y) Desa Kaibon Madiun sebesar 16,551.

2) Koefisien variabel motivasi kerja (X1) sebesar 0,248 mengindikasikan bahwa variabel motivasi kerja (X1) berpengaruh positif terhadap variabel kinerja aparat (Y) Desa Kaibon Madiun. Hal ini berarti semakin baik variabel motivasi kerja (X1) maka cenderung dapat meningkatkan variabel kinerja aparat (Y) Desa Kaibon Madiun.

3) Koefisien variabel lingkungan kerja (X2) sebesar 0,453 mengindikasikan bahwa variabel lingkungan kerja (X2) berpengaruh positif terhadap variabel kinerja aparat (Y) Desa Kaibon Madiun. Hal ini berarti semakin baik variabel lingkungan kerja (X2) maka cenderung dapat meningkatkan variabel kinerja aparat (Y) Desa Kaibon Madiun.

Pengaruh dominan variabel motivasi kerja (X1) dan lingkungan kerja (X2) terhadap variabel kinerja aparat (Y) Desa Kaibon Madiun dapat dilihat melalui standardized coefficient yang paling besar. Hasil estimasi yang tertera pada tabel di atas dapat diketahui bahwa variabel yang memiliki koefisien standardisasi terbesar adalah variabel lingkungan kerja (X2) sebesar 0,634.Dengan demikian variabel lingkungan kerja (X2) memiliki pengaruh yang paling dominan terhadap variabel kinerja aparat (Y) Desa Kaibon Madiun.

Terdapat beberapa faktor yang mempengaruhi kinerja aparat desa di antaranya motivasi kerja dan lingkungan kerja. Idealnya, semakin tinggi motivasi kerja aparat desa, maka aparat desa juga akan semakin rajin dalam melaksanakan tugasnya sebagai aparat desa. Begitu sebaliknya, semakin rendah motivasi aparat desa maka aparat desa juga semakin malas untuk melaksanakan tugasnya sebagai aparat desa. Hal ini pasti akan berdampak tidak optimalnya kinerja dari aparat desa.

Selain faktor motivasi kerja, lingkungan kerja aparat desa juga tidak kalah pentingnya di dalam meningkatkan kinerja aparat desa.Dimana lingkungan kerja mampu menciptakan kondisi kondisi material dan psikologis yang ada dalam pemerintahan desa. Maka dari itu pemerintahan desa harus menyediakan lingkungan kerja yang memadai seperti lingkungan fisik (tata ruang kantor yang nyaman, lingkungan yang bersih, pertukaran udara yang baik, warna, penerangan yang cukup maupun musik yang merdu), serta lingkungan non fisik (suasana kerja aparat, kesejahteraan aparat desa, hubungan antar sesama aparat desa, hubungan antar aparat desa dengan 
Kepala Desa, serta tempat ibadah ).

Lingkungan kerja yang baik dapat mendukung pelaksanaan kerja sehingga aparat desa memiliki semangat bekerja dan meningkatkan kinerja aparat desa. Untuk menciptakan kinerja yang tinggi, dibutuhkan adanya peningkatan kerja yang optimal dan mampu mendayagunakan potensi sumber daya manusia yang dimiliki oleh aparat desa, sehingga akan memberikan kontribusi positif bagi perkembangan pemerintah desa. Sumber daya manusia berperan dalam mengolah dan memanfaatkan sumber daya dan material sehingga menjadi produk. Oleh karena itu untuk meningkatkan kinerja, perlu diperhatikan agar sumber daya manusia dapat bekerja secara efisien dan menampilkan kinerja yang bisa memberi sumbangan terhadap produktivitas merupakan masalah mendasar dari berbagai konsep manajemen dan kepemimpinan. Kinerja mengacu pada prestasi kerja aparat diukur berdasarkan standard atau kriteria yang telah ditetapkan. Pengelolaan untuk mencapai kinerja aparat yang sangat tinggi terutama untuk meningkatkan kinerja secara keseluruhan.

\section{SIMPULAN}

Hasil penelitian ini menunjukkan bahwa berdasarkan hasil penelitian yang peneliti lakukan variabel motivasi kerja (X1) dan lingkungan kerja (X2) memberikan pengaruh yang signifikan terhadap varabel kinerja aparat (Y) Desa Kaibon Madiun.

\section{DAFTAR PUSTAKA}

Ghozali, Imam. (2011). Aplikasi Analisis Multivariate dengan Program SPSS.Semarang: Badan Penerbit Universitas Diponegoro.

Gujarati, D. N dan D. C. Porter. (2010). Dasar-Dasar Ekonometrika. Edisi Kelima.Jakarta: Salemba Empat.

Hasibuan, M. S. P. (2001). MSDM. Jakarta: Bumi Aksara.

Mathis Robert L. dan Kackson John H. (2006). Human Resource Management.Alih bahasa. Jakarta: Salemba Empat.

Nachrowi, N. D. dan H. Usman. (2006). Pendekatan Populer Pada Ekonometrika, Untuk Analisis Ekonomi dan Keuangan. Jakarta: Lembaga Penerbit FE UI. 